\section{An Application of the lean Production tool STANDARD WORK}

\author{
Sara Bragança*, Eric Costa \\ University of Minho, Guimarães, Portugal
}

Article history

Received

8 November 2014

Received in revised form

6 March 2015

Accepted

1 August 2015

${ }^{*}$ Corresponding author saraabraganca@gmail.com

\section{Graphical abstract}

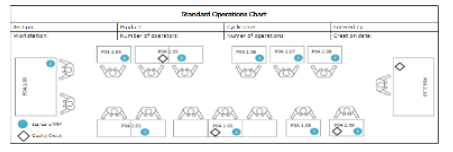

\begin{abstract}
Standard Work is a very useful tool of the Lean Production paradigm to specify standards and to establish the best methods and sequences for each process and for each worker, helping to reduce wastes. Despite its usefulness, this tool is often underused, neglected and misunderstood. Apart from that, there is a lack of literature about Standard Work. It is possible to find many papers on Lean Production in general and on some Lean tools, but there are few that focus on or describe in detail this particular tool. The main purpose of this paper is to prove the validity and show the importance and the applicability of Standard Work. The main aspects and ideas to understand this tool are described, as well as the benefits of applying it in a real world manufacturing environment. In this paper, an application example is given on a production unit of an elevators company, following the Action-Research methodology. The main findings are that Standard Work is effectively a good tool to normalize work procedures, allowing increased flexibility and production, and decreased wastes and assembly errors.
\end{abstract}

Keywords: Standard work, lean tools, lean production, waste reduction

(C) 2015 Penerbit UTM Press. All rights reserved

\subsection{INTRODUCTION}

Lean Production tries to align shop floor operations with the clients' specifics requirements, which usually include: reliable due dates, product quality, shorter lead-times and competitive prices [1] and [2]. Lean Production deeply seeks to master effectiveness on doing all that by implementing a culture of profound involvement of the workforce on waste elimination activities, right down to the most basic features of the shop floor, and on the continuous improvement of the processes [3] and [4].

Powell et al. [5] consider that the Standard Work tool is one of the basic foundations of Lean Production. Standard Work involves specifying standards for the rate of production (takt time), the required inventory, and the sequence of operator actions. These are written on worksheets located at each workstation. This Lean tool allows reducing quality errors, which is one of the major wastes that occur throughout the production process [6].

The purpose of this paper is to prove the validity, the importance and the applicability of the Lean Production tool Standard Work. The paper presents in detail how this tool should be used and the benefits of its application. Additionally, it presents a small example of its application in a real world situation, following the Action-Research methodology. This example is part of a Lean Production implementation project in an elevators company.

\subsection{STANDARD WORK}

\subsection{Overview}

"Where there is no standard, there can be no improvement" [7]. 
Standard Work is a tool used in the Lean Production paradigm, developed in 1950 by Taiichi Ohno [7]. Then, this tool was almost only used within Ohno's team, as this was a complicated tool to use, requiring the development of three diagrams: (i) parts-production capacity worktable; (ii) standard operations combination chart; and (iii) standard operations chart or standard work sheet. Additionally to those diagrams, Standard Work is composed by other three key elements [8] and [9]:

- Standard cycle time: is the cycle time for the production of a product from beginning to end in order to respond to market demand;

- $\quad$ Standard work sequence: consists of a set of tasks that are sequenced and that represent the best and safest way to perform the job. These tasks are performed by the each operator repeatedly and consistently over time;

- Standard work-in-progress: represents the minimum amount of stock that should be maintained so that it is possible to ensure production without downtimes and with a continuous flow.

Standard Work consists of a set of work procedures (a standard routine) aimed at establishing the best methods and sequences for each process and for each worker [9]. Operations must be followed exactly as they are defined with no room for improvisation; it is often referred to as an inflexible work standard [10]. To Feng and Ballard [11] Standard Work is a method where it is defined how operations should be conducted in a workstation of a production system, preventing operators to perform operations randomly.

This method does not imply that all types of work must be done in the same way, but it implies that one particular type of work is always done in the same way, regardless of the operator; and as such, individual preferences are eliminated [12]. This lack of randomness in manufacturing processes can reduce variations in cycle times because the sequence of operations is defined according to takt time in order to respond to the demand [8] and [13]. This means that the purpose of these restrictions is related to the elimination of Mura (variability) so that it is possible to improve quality, safety, efficiency and planning [10].

The standardization of work is the foundation of continuous improvement [9]. By documenting the work and by having a standard way to perform the operations, it is possible to create a foundation for the Kaizen methodology, since Standard Work involves a continuous improvement. Standard work does not imply that a work routine can never be changed (that would be a barrier to continuous improvement), but it rather implies "this is the best way we know how to do this type of work today" [12] and [14].

Standard Work may take time and effort to be implemented and maintained. However, developing and implementing it also changes the organizations' culture [14]. According to Spear and Bowen [15], it ensures the identification of the activities that add value, i.e., it defines the activities that maximize performance and minimize waste.
Some previous studies were performed to demonstrate the importance of implementing this tool. Fillingham [16] shows an application of Standard Work to reduce variation and complexity for an effective clinical practice. This author uses this tool, together with onepiece flow, 5S, pull systems and visual management to prove the application of those tools to healthcare. Other study consider Standard Work as a tool integrated with another Lean tool, the 5S [17]. To apply this tool, Whitmore [18] considers different standard documents: time observation sheets, capacity sheet, Standard Work sheet, loading diagram, combination sheets and key points sheets.

\subsection{Benefits of the Application}

Standardized operations and procedures allow producing efficiently with minimal waste, using efficient methods and rules [19]. Losonci et al. [20] stated that with a clear description of the operations to execute, operators could become polyvalent, because they have access to all information and can learn to perform new tasks, which ensures a more flexible production system.

According to Emiliani [21], if applied correctly, Standard Work can bring numerous advantages such as:

- The establishment of reference points from which it is possible to continuously improve;

- The process control;

- The reduction in variability;

- The improvement of quality and flexibility;

- The stability (i.e. predictable results);

- The predictability of abnormalities.

When implemented, Standard Work offers almost immediately performance improvements in the company, increasing productivity and decreasing the lead times. The work standardization allows operators to improve their creativity and entrepreneurship, giving them a benchmark against which they can measure their own ideas for improvement [22]. In addition, it is possible to have a greater internal transparency; more involved and disciplined operators; and a higher degree of attention to the operations by management personnel.

If they are chosen with care and concern for employees, i.e., with clear and objective information that is easily understood, the work standards can ensure that each task is viable, sustainable and safe. It should also be emphasized that the operators are free to propose different standards to be applied [10]. It may even be said that Standard Work is a precursor to excellence, a catalyst for worker satisfaction and an essential step for continuous improvement.

In many implementations of Standard Work, it is possible to observe that the operators do not initially like it, since they may feel some loss of flexibility and autonomy. However, in many cases, after some time, operators can understand the benefits of this tool and the initial problems gradually disappear [10]. Many organizations fail to implement Standard Work because they do not select correctly what they want to 
normalize. They choose areas to normalize without method or they choose to normalize it all.

Spear and Bowen [15] propose a set of rules that should be followed when seeking to implement Standard Work:

- Work should be analyzed in detail, taking into consideration the sequence, the production time, how it is performed and the results;

- The link between the customer and the supplier should be clear and direct in what regards the reception of requests or demands;

- The transportation of products in the workplace should be straightforward and simple;

- All improvements should be made following the scientific method and be supervised by a skilled person.

\subsection{RESEARCH METHODOLOGY}

During a Lean Production implementation project in an elevators company, the Standard Work tool was implemented following the Action-Research methodology. The doors assembly section of the company's metal-mechanic sector was studied. This section had 11 manual workstations and 16 workers.

The need for the standardization of work came from several aspects, such as:

- Variability of manufacturing processes;

- Inexistence of a detailed sequence of work procedures;

- $\quad$ Large diversity of products.

To use the Action-Research methodology it is required an active involvement of the researcher and a five-stage cycle should be used [23]:

(i) Diagnosis: The current status of the assembly section of the company was first analyzed, involving the analysis of several documents, conversations with the workers and video-recording of the assembly procedures. Some analysis and diagnosis tools were also used, such as sequence diagram, cause-effect diagram, spaghetti diagram and skills matrix. After this, some problems were identified, as for example, the lack of pre-defined work routines; the inexistence of a balanced work-in-process between workstations; or the appearance of recurrent errors.

(ii) Action planning: An action plan was created using the $5 \mathrm{~W} 2 \mathrm{H}$ technique. To each problem (why) a proposal was developed (what), suggesting forms to solve the problem (how). It was also identified the person responsible for the implementation (who), as well as the places to implement (where) and the moment to do it (when). (iii) Action taking: The Standard Work tool was implemented, with the creation of three distinct sheets: (a) the parts-production capacity worktable; (b) the standard operations combination chart; and (c) the standard operations chart. Additionally to these sheets, work instructions were also created for each product to assist the operators in their daily tasks.

(iv) Evaluation: The results obtained with the implementation of Standard Work were analyzed and discussed by the managers of the company and all the elements involved in this project.

(v) Learning specification: The main lessons learnt with the project were identified and some reflections about the outcomes of the project were done.

\subsection{CASE STUDY}

This section describes the phases of the Standard Work implementation process, i.e. the action taking (Stage 3) of the Action-Research methodology. The results of Stage 1 and Stage 2 will not be presented, since are not within the scope of this paper. Stage 4 and Stage 5 will be presented in the section of discussion.

Throughout this case study, samples for all documents will be provided. These samples will be related to the same workstation (P04.1.04) to maintain the consistency and provide a more reliable comparison base.

\subsection{Parts-production Capacity Worktable}

The first step in implementing Standard Work is to understand how the company works and what needs to be done. To represent this it was created a partsproduction capacity worktable that describes the capacity of each operation in terms of parts production.

To create the parts-production capacity worktable, it was necessary to first define the sequences of operations that must be performed to produce each product. The operations defined correspond to best, safest and with less waste way of producing the various products. It is also important to refer that this sequence was defined together with the head of the section and the operators to reach a consensus. Additionally, based on the standard time defined by the company, the duration of each activity was determined.

As there are only manual operations workstations, this sheet was based on a sequence diagram, where the several types of activities are identified: operations, transportations, controls, waiting and storage. Figure 1 represents one Parts-production capacity worktable for a specific product of a certain workstation. 


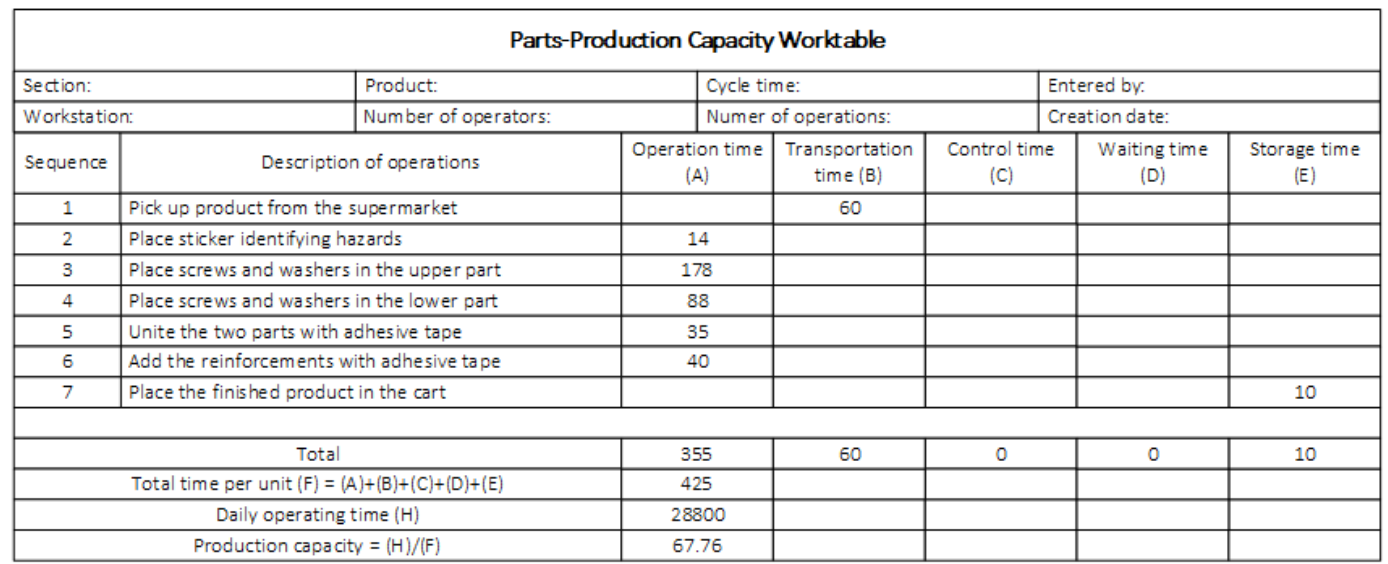

Figure 1 Parts-production capacity worktable

\subsection{Standard Operations Combination Chart}

The combination chart takes information from the partsproduction capacity worktable and displays it visually by combining the manual and machine operations showing their relationship in terms of process time.
As in this particular case there are no machine operations, this standard operations combination chart is solely based on manual operations. In Figure 2 there is an example of a standard operations combination chart for a specific product of workstation P04.1.04.

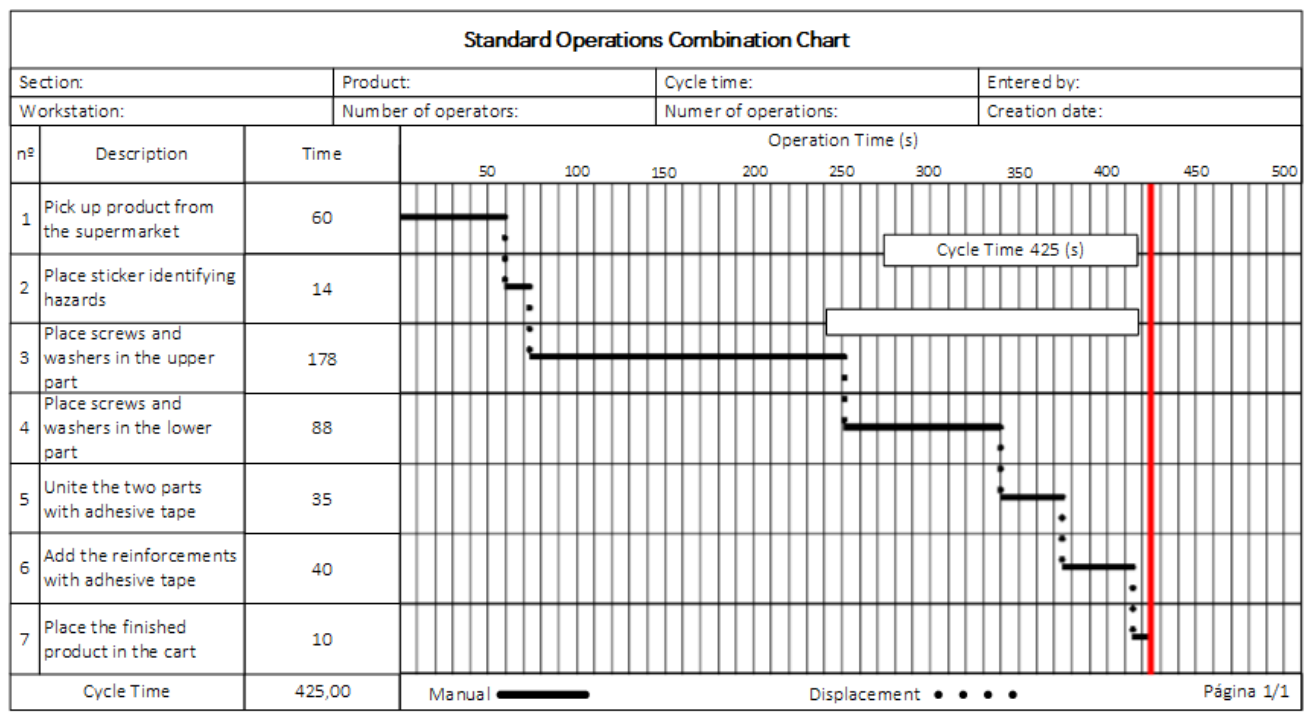

Figure 2 Standard operations combination chart

\subsection{Standard Operations Combination Chart}

The standard operations chart provides an illustration of the process with the layout. It includes much information, such as cycle time and standard work-inprocess inventory. To ensure adherence to the standards, operators should check this chart frequently.

After considering the cycle time and the sequence of work, the normalized amount of WIP (Work-InProcess) between the various workstations (SWIP Standard Work-In-Process) was defined. These quantities were determined, for each cycle, taking in consideration the cycle times of the various workstations, according to Equation 1.

$$
S W I P=\frac{\text { Cycle } \cdot \text { Time } \cdot(\text { upstream } \cdot \text { workstation })}{\text { Cycle } \cdot \text { Time } \cdot(\text { downstream } \cdot \text { workstation })}
$$

As it was intended to have a continuous production flow and no excessive stock, the amount of WIP should be such as to allow the operator of a downstream workstation to have materials to work with while the operator of an upstream workstation finalized the next product. 
For example, the workstation P04.1.02 had a cycle time of approximately $36 \mathrm{~min}$ and the products it produced went to workstation P04.1.09 that had a cycle time of about $12 \mathrm{~min}$. As the cycle time of the downstream workstation was lower than the cycle time of the upstream workstation, the inexistence of WIP would imply waiting wastes. Thus, if between these two workstations existed three items in course of manufacture (in each cycle) it would be possible to ensure that the operator of workstation P04.1.09 did not have to wait for parts if the operator of workstation P04.1.02 worked at a normal rate. As such, the quantities of SWIP (in units) considered are presented in Table 1.

Table 1 Standard work-in-process

\begin{tabular}{cccc}
\hline & \multicolumn{2}{c}{ SWIP per cycle } \\
\cline { 3 - 4 } $\begin{array}{c}\text { Upstrea } \\
\mathbf{m}\end{array}$ & $\begin{array}{c}\text { Cycle } \\
\text { Time } \\
(\mathbf{m i n})\end{array}$ & $\begin{array}{c}\text { Downstrea } \\
\mathbf{m} \\
\text { Workstatio } \\
\mathbf{n}\end{array}$ & Quantity \\
\hline P04.1.00 & 17.22 & P04.1.10 & 2 \\
P04.1.01 & 15.33 & P04.1.02 & 0 \\
P04.1.02 & 36.22 & P04.1.09 & 3 \\
P04.1.03 & 10.63 & P04.1.09 & 1 \\
P04.1.04 & 19.59 & P04.1.10 & 2 \\
P04.1.05 & 43.58 & P04.1.09 & 4 \\
P04.1.06 & 32.71 & P04.1.10 & 1 \\
P04.1.07 & 9.77 & P04.1.10 & 1 \\
P04.1.08 & 10.65 & P04.1.10 & 1 \\
P04.1.09 & 12.44 & P04.1.10 & 1 \\
P04.1.10 & 10.23 & P04.1.05 & 1 \\
\hline
\end{tabular}

As the standard operation combinations charts were created for each workstation individually, and not for a set of workstations, the standard operation charts should also have to be about each workstation separately. However, as this type of information would not be a great asset to serve as good visual information, it was decided by the company to create a standard work sheet of the entire section that can be seen in Figure 3.

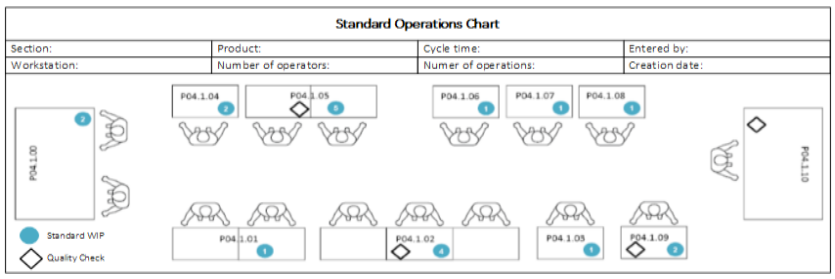

Figure 3 Standard operation chart

The SWIP indicated refers to the amount of WIP that existed between the workstation with the blue marker and the following workstation. Two of the locations marked as having quality control (P04.1.02 and P04.1.05) were workstation that received materials from other workstation so that there would always be a verification of the conformity of the product.

\subsection{Work instructions}

Work instructions often appear associated with Standard Work since they document, in a simplified form, the standard procedures set through Standard Work [24]. As such, in this project, work instructions were created for each product, which described the various steps that should be followed in their assembly.

These sheets are based mainly on visual information (photographs and diagrams) to simplify its understanding by the operators. In Figure 4 it is possible to see an example of a work instruction created for a specific product.

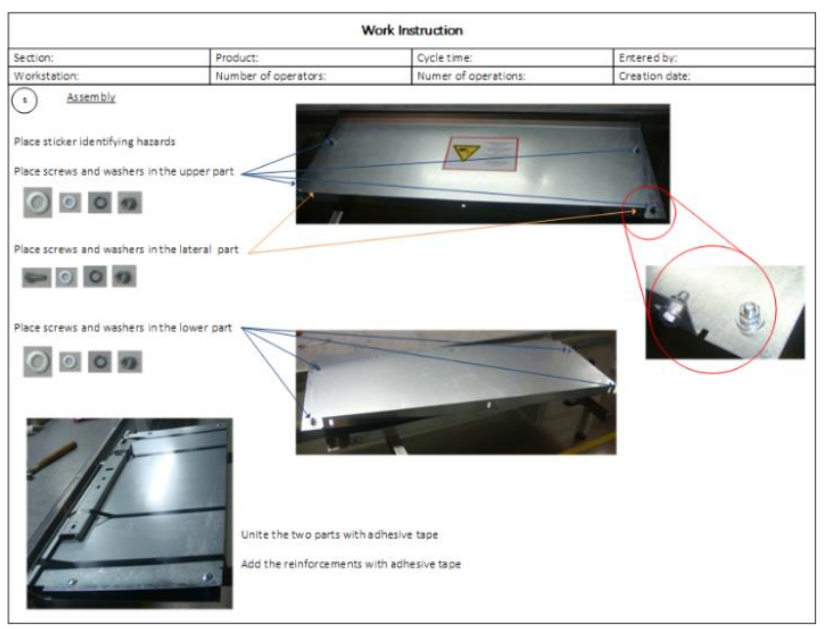

Figure 4 Example of a work instruction

\subsection{DISCUSSION}

The representation of the shop floor situation in the parts-production capacity worktable allowed seeing that the capacity in this particular workstation was 67.76 parts. This result shows that, at that rate, it is possible to produce approximately 67 products in an 8-hour work day (28800 seconds). This was a relatively good capacity, since it was slightly higher than the takt time.

Despite showing almost the same information than the previous sheet, the standard operations combination chart permits a better visual representation of the workstation's operations and cycle time.

Finally, the standard operations chart identifies all the places where Standard Work-In-Process (and the respective quantity) can be found and the all the quality control points. In this example the amounts of SWIP needed to maintain a continuous workflow between workstations is very small, being the largest value only 4 units. It can also be seen that in the eleven 
workstations, four of them represent quality control checkpoints.

In this sense, the application of Standard Work allowed to define standard manufacturing procedures (which are explained in detail in visual information in the work instructions) and normalized cycle times.

The creation of work instructions had implications on the company's situation, as it was an aid to the new employees (that could learn quickly and were not so dependent on the knowledge transferred from other operators).

The products analyzed were those that were produced the most at that specific time (resulting from an $A B C$ analysis). However, in a few years, when the company starts to manufacture new models, this trend will be reversed and these products will only be produced by specific orders (repairs and parts supply). As such, in the future, as the development of all these tasks will not be part of the daily work routine, operators will naturally forget some procedures. As such, the documentation of all operations through the work instructions will be helpful in the future to assist operators in those circumstances.

\subsection{CONCLUSION}

Quite often solutions that seem very simple can bring great improvements at low costs if applied correctly. Taking into account the key idea of Lean Production "doing more with less" the implementation of Standard Work followed indeed this thought, since it did not require a high investment from the company.

The standardization of work procedures, through Standard Work and work instructions, gave the company a base for the documentation of manufacturing processes, components and tools. These documents served to provide greater flexibility to the section and to increase its productivity, to the extent that they enable the reduction of several wastes and manufacturing errors.

Thus, the advantages of applying Standard Work proved to be:

- Enhancing workers' polyvalence

- Allowing a better usage of the workers' working time;

- $\quad$ Lowering the processes' variability

- Enabling a better control of the work processes and operations;

- $\quad$ Reducing errors in quality.

This paper represents an important step to give more visibility to this Lean tool, addressing the problem of the lack of literature focused on more detailed description of the application procedures and benefits that this tool can bring. Therefore, this study contributes to the literature on Standard Work, proving the validity of the tool with a detailed application in a real-world context. Future work should be done by developing studies in different areas and focused only on this Lean tool, in order to show its usefulness.

\section{References}

[1] Shingo, S. 1989. A Study of the Toyota Production System: From an Industrial Engineering Viewpoint. New York: Productivity Press.

[2] Womack, J., and D. Jones. 1996. Lean Thinking - Banish Waste and Create Wealth in Your Corporation. New York: Simon \& Schuster.

[3] Dinis-Carvalho, J., F. Moreira, S. Bragança, E. Costa, A. Alves, and R. Sousa. 2015. Waste Identification Diagrams. Production Planning and Control. 26(3): 235-247.

[4] Sahwan, M., M. Ab Rahman, and B. Deros. 2012. Barriers to Implement Lean Manufacturing in Malaysian Automotive Industry. Jurnal Teknologi. 59(2): 107-110.

[5] Powell, D., E. Alfnes, J. Strandhagen, and H. Dreyer. 2013. The Concurrent Application of Lean Production and ERP: Towards An ERP-Based Lean Implementation Process. Computers in Industry. 64(3): 324-335.

[6] Zahraee, S., A. Hashemi, A. Abdi, A. Shahpanah, and J. Rohani. 2014. Lean Manufacturing Implementation Through Value Stream Mapping: A Case Study. Jurnal Teknologi. 68(3): 119-124.

[7] Ohno, T. 1988. Toyota Production System: Beyond Largescale Production. Cambridge: Productivity Press.

[8] Monden, Y. 1998. Toyota Production System: An integrated approach to Just-In-Time. Norcross: Engineering and Management Press.

[9] The Productivity Press Development Team. 2002. Standard Work for the Shop Floor. New York: Productivity Press.

[10] Arezes, P., D. Carvalho, and A. Alves. 2010. Threats and Opportunities for Workplace Ergonomics in Lean Environments. International Annual EurOMA Conference Managing Operations in Service Economics (EurOMA), 2010. Porto, Portugal.

[11] Feng, P., and G. Ballard. 2008. Standardized Work from Lean Theory Perspective. Annual Conference of the International Group for Lean Construction, 2008. Manchester, United Kingdom.

[12] Wigglesworth, M., and T. Wood. 2012. Management of Chemical and Biological Samples for Screening Applications. Weinheim: John Wiley \& Sons.

[13] Womack, J., and D. Jones. 1996. Beyond Toyota: How to Root Out Waste and Pursue Perfection. Harvard Business Review. 74(5): 1-16.

[14] Duggan, K. 2012. Creating Mixed Model Value Streams: Practical Lean Techniques for Building to Demand. Florida: CRC Press.

[15] Spear, S., and H. Bowen. 1999. Decoding the DNA of the Toyota Production System. Harvard Business Review. 77(5): 95-106.

[16] Fillingham, D. 2007. Can Lean Save Lives? Leadership in Health Services. 20(4): 231-241.

[17] Ben-Tovim, D. I., et al. 2008. Redesigning Care at the Flinders Medical Centre: Clinical process redesign using "lean thinking". Medical Journal of Australia. 188(6): 27-31.

[18] Whitmore, T. 2008. Standardized Work. Manufacturing Engineering.

[19] Lim, K., P. Ahmed, and M. Zairi. 1999. Managing waste and looking beyond: the IMI approach. The TQM Magazine. $11(5): 304-310$.

[20] Losonci, D., K. Demeter, and I. Jenei. 2011. Factors Influencing Employee Perceptions in Lean Transformations. International Journal of Production Economics. 131(1): 3043.

[21] Emiliani, M. 2008. Standardized Work for Executive Leadership. Leadership \& Organization Development Journal. 29(1): 24-46.

[22] Toussaint, J., and L. Berry. 2013. The Promise of Lean in Health Care. Mayo Clinic Proceedings. 88(1): 74-82.

[23] O'Brien, R. 1998. An Overview of the Methodological Approach of Action Research. Faculty of Information Studies, University of Toronto. 
[24] Bragança, S., A. Alves, E. Costa, and R. Sousa. 2013. The Use of Lean Tools to Improve the Performance of an Elevators
Company. International Conference on Integrity, Reliability and Failure (IRF), 2013. Funchal, Portugal. 